\title{
Bottom-up vs Top-down Model: The Perception of Reading Strategies among Thai University Students
}

\author{
Prathomwat Suraprajit \\ Faculty of Management Sciences, Kasetsart University, Thailand
}

\begin{abstract}
Reading strategies have been declared as a vital role in reading comprehension among the students whose English is their second or foreign language. The use of reading strategies would help the learners to deeper understand the text so that they could achieve their tasks. The present study then investigates the use of reading strategies by focusing on the bottom-up and top-down models for both academic and business texts among Thai students in tertiary level. Two hundred-seventy non-simple random undergraduate students participated in this study. The forty-five-item questionnaire was delivered to the participants. The findings were that top-down reading strategies were used the most for both academic and business reading, whereas bottom-up reading strategies were reported the least on both kinds of text. The results suggest that larger numbers of participants, correction between the proficiency and the use of strategies, in-depth interview, and strategies used between low and high proficient readers should be examined.
\end{abstract}

Index Terms - top-down model, bottom-up model, academic text, business text

\section{INTRODUCTION}

English plays a vital role for all society around this planet. Not only speaking, writing or listening, but reading is also a very necessary for those who prefer to communicate effectively. Chawwang (2008) stated that reading is the most important skill because it is the useful tool for acquiring knowledge. Used in both studying and living life, English is a lifelong skill for many people (Kucukoglu, 2013). Then, without ability to read well, opportunities for personal fulfilment and job success inevitably will be lost (Anderson et al., 1985). If students expect to get the deepest understanding of what they read, they should have the techniques or strategies for reading. The ability to read proficiently is significantly related to how much a person can achieve in his or her personal and professional life (Block \& Israel, 2005).

Reading can also serve many purposes. Firstly, it makes the reader relax. Lots of people prefer to read their favorite books in their spare time. Secondly, reading is crucial for business purposes. The business people face a ton of emails in their daily work. The reading skill then supports a lot on this interaction. Lastly, the readers may read for knowledge. For example, the students are usually required to read the journals or academic books in all courses they registered. The stated reading purposes are some reasons that present how important the reading skill is. In Thailand, reading is also very important for Thai people, especially English reading. That is because English is a medium language for Thai people for cooperating with the neighbors in AEC (Asean Economics Community) countries and other foreign countries which use English for communicating in various purposes.

However, reading is still considered a difficult task for most of Thai people. According to PISA (2015), the report from the program for international student assessment showed that Thailand shared of low achievers in reading below the Organization for Economic Co-operation and Development (OECD) average which is about $20 \%$ of students in OECD countries. The reports from EF EPI (2017) also indicated that English proficiency of Thais is very low and below the average.

The difficulties in reading among Thais are also found in many previous studies. Hayikaleng, Nair \& Krishnasamy (2016) also comment that Thai students usually face difficulty when they read the academic books that is consistent with the study of Kasemsap \& Lee (2015) who also stated that Thai students are weak in English reading comprehension. Then, there are some scholars who searched on the reasons why reading is a difficult task among Thai people. Chawwang (2008) investigated the English problems among Thai students. The results showed that the problems cover three areas including sentence structure, vocabulary, and reading comprehension. Another idea comes from Pangsapa (2012) who did a research on the English reading problems among Thai editorial staff. Her findings revealed that four main reading problems includes not understanding technical words meaning, not knowing the word meaning, facing with complex and very long sentences with many dependent clauses or paragraphs, and unfamiliar words.

Therefore, the reading strategies are important and useful for solving these reading problems or difficulties. Garner (1987) stated that reading strategies are as generally deliberate, playful activities undertaken by active learners, many times to remedy perceived cognitive failure. According to Brown (2007a), reading strategies could be defined as the specific methods of approaching a problem or task, modes of operation for achieving a particular ends, planned designs 
for controlling and manipulating certain information. There are many strategies that are useful for reading comprehension. However, the present study is designed to investigate the top-down and bottom up reading strategies among Thai tertiary students when they read academic and business texts.

\section{A. Top-down Model}

The concept of this strategy is about guessing the meaning of the target reading material. Goodman (1971) firstly comment on top-down model as 'a psycholinguistic guessing game', by showing that the readers predict text's meaning primarily based on their existing or background knowledge. Moreover, this model is applied when readers interpret assumptions and draw inference or they need to find out the overall purpose of the text or to get main ideas of the text (Nuttall, 1996). In addition, the top-down model is recognized under cognitive process that the processing of a text begins in the mind of the reader. The meaning which is retrieved from the reader's knowledge, expectation, assumption, and questions to the text is reconfirmed by identifying the letters and words appeared on the text (Aebersold \& Field, 1997). In the other words, the readers activate their experience and background or world knowledge in order to understand the text. Correll \& Eisterhold (1998) also discussed that reader's prediction and background knowledge play a vital role in this model. Using as a tool to predict the text, construct a goal of reading, and self-monitor, this model is very much like the general strategies (Block, 1986) or global strategies (Sheorey \& Mokhtari, 2001). In addition, this model is still considered as concept-driven and dependent upon what the reader brings to the text which could be their own intelligence and experience to understand a text (Brown, 2007b; Abbott, 2010; and Lui, 2010).

\section{B. Bottom-up Model}

This model is declared as a decoding process of constructing meaning at the "bottom", e.g. letters or words to the larger units at "the top", e.g. phrases, clauses, and intersentential linkages (Carrell \& Eistenhold, 1983). Readers begin with decoding letters, words, and syntactic features of a text, then they build textual meaning. They work mainly from the text but ignore reader's prior or background knowledge. Another idea towards this model is from Dole et al. (1991). They stated that this model refers to a single-direction part-to-whole processing of a written or printed text. It is also known as "decoding". Moreover, this model is defined as assembling the reading jigsaw of text by correcting the right pieces together. By putting reading puzzle or individual units of text together, it helps constructing an overall interpretation of the text (Celce-Murcia, 2001). Moreover, Brown (2007b) defined bottom-up model as using metal data-processing device to put linguistic signal (letters morphemes, syllables, words, phrases, and discourse makers) in order. In addition, Eunjeo (2009) comment that this model is defined as "focusing on individual words, pausing for grammatical difficulties and repeated readings. Finally, Dambacher (2010) discussed that bottom-up model processes account for elaboration of sensory signals and therefore reflect operations giving rise to the retrieval of a word's mental representation.

\section{Research Objectives}

1) To investigate the types and frequency used of reading strategies towards academic texts based on top-down and bottom-up model among university students in Thailand.

2) To investigate the types and frequency used of reading strategies towards business texts based on top-down and bottom-up model among university students in Thailand.

3) To compare the reading strategies the participants used between academic and business texts.

\section{LITERATURE REVIEWS}

Some scholars (Block, 1986; Carrell, 1989; and Kong, 2006) divided reading strategies into two main groups. The first group is about bottom-up or local strategies which are related to the letters, words, and text information, and topdown or global strategies which are related to background knowledge, text gist, and textual organization. Another group consists of cognitive strategies or strategies that are related to the target language and metacognitive strategies which concern about self-management and self-regulation. The present study then focus on the first group which is about bottom-up and top-down strategies.

Related to bottom-up and top-down models of reading strategies, there are many previous studies conducted on the field. Oranpattanachai (2010) investigated the effect of reading proficiency on the reading process of Thai preengineering students. The finding revealed that the differences between the high and low proficiency readers were the frequency of perceived strategy use and the frequency of perceived top-down strategy use. Yildiz-Genc (2009) examined the relationship between L1 and L2 reading focusing on the nature of reading strategies employed by Turkish EFL learners in their L1 and L2. The results showed that the participants used both bottom-up and top-down strategies while reading the L2 text. However, it was observed that more top-down strategies were employed in both L1 and L2, whereas bottom-up strategies were less in number and variety. The results from the work of Geladari, Griva \& Mastrothanasis (2010) also showed that proficiency readers used a great diversity of top-down strategies which is different from the low level readers who appear to rely on bottom-up strategies for word decoding and are ignorant of the reading process. Boonkongsaen, Sujinpram \& Verapreyagoon (2016) examined the strategies used in English reading by Thai science students. The finding showed that the participants likely rely on "bottom-up" strategies. Some researchers (Huang, Chern, \& Lin, 2009; Yuksel \& Yuksel, 2012; Surattanasing \& Gampper, 2013; Saengpakdeejit, 
2014; Nisbet \& Huang, 2015; Wright, 2015; Yousefian, 2015; and Zare \& Maftoon, 2015) still investigated the reading strategies among the students based on the problem-solving strategies that is referred to bottom-up, global strategies that is related to top-down, and supporting strategies that is mentioned to bottom-up (Mokhtari \& Sheorey, 2002).

\section{RESEARCH METHOD}

\section{A. Participants}

Being members of the faculty of Management Sciences and faculty of Economics, a non-random sample 270 undergraduate Thai university students are recruited to participate in the present study. They are 35 males $(25.90 \%)$ and 100 females $(74.10 \%)$ from the faculty of Economics and 25 males (14.82\%), 114 females (84.44\%) and 3 LGBT $(0.74 \%)$ from the faculty of Management Sciences. Those who are from the faculty of Management Sciences took an Analytical Reading for Business course which is about business reading, whereas Technical English course which is about academic reading was enrolled by the members of the faculty of Economics.

\section{B. Instrument}

Adopted from Fevziye (2006) who studied the awareness of reading strategies among the university students in Turkey, the questionnaire used in the present study was designed to gain the data about reading strategies by using bottom-up or top-down strategies among Thai undergraduate students. Consisted of two parts that are personal information and reading strategies used, the questionnaire presents 45 items with 15 bottom-up strategies and 30 topdown strategies divided into three sections including "strategies used before reading a text (pre-reading)", "strategies used while reading a text (while-reading)", and "strategies used after reading a text (post-reading)". The subjects are requested to rate the frequency of use for each strategy with a five-point Likert Scale ranging from (1) never or not sure, (2) rarely, (3) sometimes, (4) often, and (5) almost always.

\section{Data Collection and Analysis}

The questionnaire was delivered to each participant to complete at the end of the course. The researcher explained that the rating has no effect on their final grade. Then, they should answer or rate their opinion truly. Moreover, the participants were informed that their rating would be benefit for developing the reading course. The data gained from the questionnaire was then analyzed by using descriptive analysis.

\section{RESULTS}

TABLE. I

The Most Used StrategIES In REAdING ACADEMIC TEXT

\begin{tabular}{clcc}
\hline No. & Reading strategy & Mean & SD \\
\hline 1 & Visuals (graphs, pictures, \& tables) are important for my reading. & 3.87 & 1.00 \\
2 & I look at the comprehension questions before reading the text. & 3.85 & 1.13 \\
3 & I change reading speed depending on the difficulty of a text. & 3.76 & 1.02 \\
4 & I use my background knowledge about the topic for my reading. & 3.71 & 0.94 \\
5 & I consider the title to predict the content. & 3.66 & 0.93 \\
\hline
\end{tabular}

Table 1 presents the five most used strategies in academic reading. They are 1) "visuals that are included graphs, pictures, and tables are important for my reading" that is used before reading a text and is under the top-down strategy, 2) "I look at the comprehension questions before reading the text" that is used while reading a text and is under the topdown strategy, 3) "I change reading speed depending on the difficulty of a text" that is used while reading a text and is under the bottom-up strategy, 4) "I use my background knowledge about the topic for my reading" that is used before reading a text and is under the top-down strategy, and 5) "I consider the title to predict the content" that is used before reading a text and is under the top-down strategy, respectively. Then, according to the average scores on the five-point Likert scale $(1.0-2.4=$ low use, $2.5-3.4=$ medium use, and $3.5-5.0=$ high use $)$, the average score of all five most used strategies were defined as high use. 
TABLE II.

The Least Used StrategIES IN READING ACADEMIC TeXT

\begin{tabular}{|c|c|c|c|}
\hline No. & Reading strategy & Mean & SD \\
\hline 1 & I read aloud the entire text. & 2.26 & 1.08 \\
\hline 2 & $\begin{array}{l}\text { After reading the text in detail, I evaluate the text and } \\
\text { the writer's viewpoint. }\end{array}$ & 2.36 & 0.99 \\
\hline 3 & $\begin{array}{l}\text { I try to understand the text without translating it into my } \\
\text { native language (Thai). }\end{array}$ & 2.50 & 1.18 \\
\hline 4 & I use slashes to divide a sentence grammatically. & 2.56 & 1.09 \\
\hline 5 & If I face the difficult parts, I read aloud. & 2.62 & 1.29 \\
\hline
\end{tabular}

Table 2 demonstrates the five least used strategies in academic reading. According to the average scores on the fivepoint Likert scale, the average mean score of the first two least use "I read aloud the entire text" that is used while reading a text and is under the bottom-up strategy, and "after reading the text in detail, I evaluate the text and the writer's viewpoint" that is used after reading a text and is under the top-down strategy were defined as low use. Then, the remains, "I try to understand the text without translating it into my native language" that is used while reading a text and is under the top-down strategy, "I use slashes to divide a sentence grammatically" that is used while reading a text and is under the bottom-up strategy, and "If I face the difficult parts, I read aloud" that is used while reading a text and is under the bottom-up strategy were defined as medium use.

TABLE.III

The Most Used StRategIEs In REAding Business TeXT

\begin{tabular}{llll}
\hline No. & Reading strategy & Mean & SD \\
\hline 1 & I consider title to predict the content. & 3.91 & 0.91 \\
2 & I use my background knowledge about the topic for my reading. & 3.88 & 0.88 \\
3 & Visuals (graphs, pictures, \& tables) are important for my reading. & 3.85 & 0.96 \\
4 & I link the content with what I already know. & 3.74 & 0.84 \\
5 & I underline important parts. & 3.72 & 1.06 \\
\hline
\end{tabular}

Table 3 presents the five most used strategies in business reading. They are 1) "I consider title to predict the content" that is used before reading a text and is under the top-down strategy, 2) I use my background knowledge about the topic for my reading" that is used before reading a text and is under the top-down strategy, 3) "visuals that are included graphs, pictures, and tables are important for my reading" that is used before reading a text and is under the top-down strategy, 4) "I link the content with what I already know" that is used while reading a text and is under the top-down strategy, and 5) "I underline important parts" that is used while reading a text and is under the top-down strategy, respectively. Then, according to the average scores on the five-point Likert scale, the average score of all five most used strategies were defined as high use.

TABLE. IV

THE LEAst UsEd StRATEGIES IN READING Business TEXT

\begin{tabular}{clcc}
\hline No. & Reading strategy & Mean & SD \\
\hline 1 & I read aloud the entire text. & 2.28 & 0.96 \\
2 & $\begin{array}{l}\text { After reading the text in detail, I evaluate the text and } \\
\text { the writer's viewpoint. }\end{array}$ & 2.51 & 0.92 \\
& I pay attention on tenses. & 2.52 & 0.95 \\
3 & I use slashes to divide a sentence grammatically. & 2.54 & 1.02 \\
5 & I ask questions related to the text or what I have read. & 2.70 & 0.82 \\
\hline
\end{tabular}

Table 4 demonstrates the five least used strategies in business reading. The first least used were "I read aloud the entire text" that is used while reading a text and is under the bottom-up strategy was reported as a low use, whereas "after reading the text in detail, I evaluate the text and the writer's viewpoint" that is used after reading a text and is under the top-down strategy, "I pay attention on tenses" that is used while reading a text and is under the bottom-up strategy, "I use slashes to divide a sentence grammatically" that is used while reading a text and is under the bottom-up strategy, and "I ask questions related to the text or what I have read" that is used after reading a text and is under the top-down strategy, were defined as medium use.

\section{DISCUSSION}

According to the findings of the present study, the reading strategies that were employed the most on both academic and business texts by the participants are the top-down strategies. Among the five most strategies, four top-down 
strategies were employed when the participants read the academic texts, whereas five top-down strategies were used during reading the business texts. By using the top-down strategies, the participants predicted the information on the text, and then used their own background knowledge or experiences to comprehend the texts (Goodman, 1971; Block, 1986; Grabe, 1991; Correll \& Eisterhold, 1998; Sheorey \& Mokhtari, 2001; and Kong, 2006). Indicated as the most strategy used, the participants have their purposes in their mind by guessing what the idea or content of the text is going to be about together with using their background knowledge to comprehend and overview the text (Yousefian, 2015). The finding of the present study then is relevant with those appeared on the studies of Huang, Chern, \& Lin (2009); Oranpattanachai (2010); Yousefian (2015); Boonkongsaen, Sujinpram, \& Verapreyagoon (2016); and Yildiz-Genc (2009). Huang, Chern, \& Lin (2009) discussed on their findings that the use of reading strategies helps the learners in gaining the comprehension and the global strategies (top-down strategies) supported a lot in better comprehending, especially for those who are not proficient. Yildiz-Genc (2009) discussed that by using more top-down strategies in L2 reading, L2 readers may try to avoid the negative effects of limited L2 proficiency through the use of background knowledge about the topic or even the prediction about the content of the text. Then, Geladari, Griva \& Mastrothanasis (2010) and Oranpattanachai (2010) comment that high proficiency L2 learners used more top-down strategies than those who are low proficiency. It may imply that the Thai participants who participated in the present study have a proficient reading ability. Moreover, as this model was frequently used on the pre-reading stage (strategies used before reading a text), it may imply that most students seem to have a plan or preparation before reading a text. In the other words, they initially thought about what they are going to face on the reading materials so that they may get an overview towards the ideas stated by the writer.

The least used strategies for both academic and business reading are bottom-up. Most of participants did not like to read aloud, use slashes to divide a sentence grammatically or even pay attention on the tense. The finding of the present study is consistent with the studies of Ledger \& Merga, (2018); Yousefian, (2015); Oranpattanachai, (2010); and Yuldiz-Genc, (2009). "Reading aloud the entire text" is considered the least used strategy. It may imply that the participants did not see the importance of the oral language in second language. However, there are some scholars who pay attention on the significance of the oral language which is vital in L2 reading. Ninsuwan (2015) stated that reading aloud boosted the students to have more self-confidence to pronounce the different or unfamiliar words and it could build up potential for students to memorize words. Moreover, being the least used strategies for both academic and business reading, bottom-up strategies were less employed while or after reading text. It may imply that by less using the stated strategies, the readers do not want to waste their time while or after reading.

There is no different on the most and least strategies used on both academic and business reading. As revealed on the results, when the Thai university students read both academic and business reading, top-down strategies are the most used, whereas bottom-up strategies are the least used.

\section{CONCLUSION}

In general, the results of the present study suggest that both top-down and bottom-up strategies were employed in all stages including pre-reading, while-reading, and post-reading. However, top-down strategies were mostly used by both academic and business reading with a high use, whereas bottom-up model was used the least by both academic and business reading with both medium and low uses. In the other words, there is no differences in the most and least uses in reading both academic and business texts. Moreover, the findings of this study provided some insight into the use of reading strategies among Thai university students. It implies that they seem to frequently use reading strategies before they read a text. It means that they have a plan for managing with their tasks or assignments in order to gain a preview of the reading material or a deeper comprehension towards the text. In contrast, the Thai university students less use the reading strategies during and after reading texts. It is suggested that the future research should look at the effects of the reading strategies use at these three stages including pre-reading, while-reading, and post-reading. Different type of texts plays no impacts on reading strategies usage which appeared on the results that the most and least use of both academic and business readings are the same.

\section{REFERENCES}

[1] Abbott, M. (2010). An introspective study of Arabic and Mandarin Speakers reading comprehension strategies. TESL Canada Journal/ Revue TESL Du Canada, 28(1), 14-40.

[2] Aebersold, J.A. \& Field, M.L. (1997). From Reader to Reading Teacher. Cambridge: Cambridge University Press.

[3] Anderson, R. Hiebert, E. Scott, J. \& Wilkinson, I. (1985). Becoming a nation of readers: The report of the commission on reading. Washington DC: National Institute of Education and the Center for the Study of Reading.

[4] Block, E.L. (1992). See how they read: comprehension monitoring for L1 and L2 readers. TESOL Quarterly, 26(2), 319-412.

[5] Block, C. \& Israel, S. (2005). Reading first and beyond: The complete guide for teachers and literacy coaches. Thousand Oaks, CA: Corwin Press.

[6] Boonkongsaen, N. Sujinpram, N. \& Verapreyagoon, J. (2016). English Reading Strategies Used by Thai Students with Different English Exposures from Different Educational Institutions. ABAC Journal, 36(1), 47-67.

[7] Brown, H.D. (2007a). Principles of Language Learning and Teaching. New York: Pearson Education.

[8] Brown, H.D. (2007b). Teaching by Principles: An Interactive Approach for Language Pedagogy. $3^{\text {rd }}$ Edition. New York: Pearson Education. 
[9] Carrell, P.L. (1989). Metacognitive Awareness and Second Language Reading. The Modern Language Journal, 73(2), 121-134.

[10] Carrell, P.L. \& Eisterhold, J.C. (1983). Schema Theory and ESL Reading Pedagogy. TESOL Quarterly, 17(4), 553-573.

[11] Celce-Murcia, M. (2001). Teaching English as a Second or Foreign Language. Boston: Heinle and Heinle.

[12] Chawwang, N. (2008). An investigation of English reading problems of Thai $12^{\text {th }}$-grade students in Nakhonratchasima educational regions 1, 2, 3, and 7. Thesis, M.A. in English, Srinakharinwirot University.

[13] Dambacher, M. (2010). Bottom-up and top-down processes in reading. Postsdam: Universitatsuerlag Postsdam.

[14] Dole, J.A., Duffy, G.G., Roehler, L.R., \& Pearson, D.D. (1991). Moving from the old to the new: Research on reading comprehension instruction. Review of Education Research, 61(2), 239-264.EF English Proficiency Index (EF EPI). (2017). Retrieved on January 15, 2017 from http://www.ef.co.th/epi/regions/asia/thailand.

[15] Eunjeo, K. (2009). Transfer and variations of L1 reading. The Journal of Studies in Language, 25(2), 223-246.

[16] Fevziye, K. (2006). Student's awareness of reading strategies. Thesis, M.A. in Teaching English as a Foreign Language. Bilkent University.

[17] Garner, R. (1987). Metacognition and reading comprehension. New Jersey: Albex.

[18] Geladari, A., Griva, E. \& Mastrothanasis, K. (2010). A record of bilingual elementary student's reading strategies in Greek as a second language. Procedia-Social and Behavioral Sciences, 2(2), 3763-3769.

[19] Goodman, K.S. (1971). Psycholinguistic Universals in the reading process. In P. Pimsleur \& T. Quinn (Eds.), The psychology of second language learning. Cambridge: Cambridge University Press.

[20] Grabe, W. (1991). Current development in second language reading research. TESOL Quarterly, 25(3), 375-406.

[21] Hayikaleng, N. Nair, S.M. \& Krishnasamy, H.N. (2016). Thai students' motivation on English reading comprehension. International Journal of Education and Research, 4(6), 477-486.

[22] Huang, H. Chern, C. \& Lin, C. (2009). EFL learner's use of online reading strategies and comprehension of texts: An exploratory study. Computer \& Education, 59, 13-26.

[23] Kasemsap, B. \& Lee, H.Y. (2005). The Reading Matrix. An International Online Journal, 15(2), 101-117.

[24] Kong, A. (2006). Connections between L1 and L2 Readings: Reading strategies used by for Chinese adults readers. The Reading Matrix, 6(2), 19-45.

[25] Kucukoglu, H. (2013). Improving reading skills through effective reading strategies. Akdeniz Language Studies Conference 2012. Procedia-Social and Behavioral Sciences. 70, 709-714.

[26] Ledger, S. \& Merga, M.K. (2018). Reading Aloud: Children's Attitudes toward being Read to at Home and at School. Australian Journal of Teacher Education, 43(3), 124-139.

[27] Lui, F. (2010). A short analysis of the nature of reading. English Language Teaching, 3(3), 152-157.

[28] Mokhtari, K. \& Sheorey, R. (2002). Measuring ESL Students' Awareness of Reading Strategies. Journal of Development Education, 25(3), 2-10.

[29] Ninsuwan, P. (2015). The Effectiveness of Teaching English by Using Reading Aloud Technique towards EFL Beginners. Procedia-Social Behavioral Sciences, 197, 1835-1840.

[30] Nisbet, D.L. \& Huang, J. (2015). Reading strategy use and reading proficiency of EFL students in China. The Asian Journal of Applied Linguistics, 2(3), 202-212.

[31] Nuttall, C. (1996). Teaching reading skills in a foreign language. Oxford: Heineman.

[32] OECD (Economic Co-operation and Development) (2015). PISA 2015 Results in Focus. http:www.oecd.org/pisa/pisa-2015results-in-focus.pdf (accessed 14/02/2018).

[33] Oranpattanachai, P. (2010). Perceived Reading Strategies Used by Thai Pre-Engineering Students. ABAC Journal, 30(2), $26-42$.

[34] Pangsapa, N. (2012). A Study of English Reading Problems and Strategies of Thai Editorial Staff. Thesis M.A. in English, Srinakharinwirot University.

[35] Saengpakdeejit, R. (2014). Thai Third-Year Undergraduate Students' Frequent Use of Reading Strategies with a Focus on Reading Proficiency and Gender. Kasetsart Journal (Social Sciences), 35, 103-112.

[36] Sheorey, R., Mokhtari, K. (2001). Differences in the metacognitive awareness of reading strategies among native and nonnative readers. System, 29, 431-449.

[37] Surattanasing, N. \& Gampper, C. (2013). A survey study of reading strategies in English textbooks and/or academic journals used by female laboratory technicians at Jetanin Institute for Assisted Reproduction. Thesis, M.A. Teaching English as a Foreign Language, Thammasat University.

[38] Wright, J.M. (2015). Metacognitive Awareness of Reading Strategies Reported by Emirati Learners Enrolled in Post-Secondary Education in the United Arab Emirates. Thesis, Doctorate of Education, School of Education and Professional Studies, Griffith University.

[39] Yildiz-Genc, Z.S. (2009). An investigation on strategies for reading in first and second language. 18 ${ }^{\text {th }}$ ISTAL. Retrieved on February $18^{\text {th }}, 2018$ from http://www.enl.auth.gr/symposium18/paper/41_YILDIZ_GENC.pdf.

[40] Yousefian, V. (2015). Reading Strategies Used by Iranian EFL Learners While Reading Academic Texts. The Journal of Applied Linguistics, 8(17), 192-204.

[41] Yuksel, I. \& Yuksel, I. (2012). Metacognitive Awareness of Academic Reading Strategies. WCLTA2011. Procedia-Social and Behavioral Sciences, 31, 894-898.

[42] Zare, J. \& Maftoon, P. (2015). Reading Strategies Use and Field of Study: A Mixed-Methods Study. Iranian Journal of Applied Language Studies, 7(1), 171-196. 


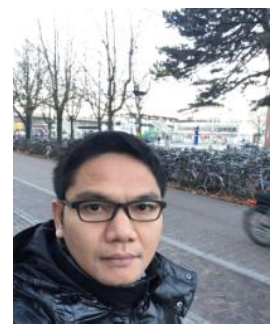

Prathomwat Suraprajit received his M.A in English for Communication from Burapha University, Thailand. He is now a full time lecturer at Kasetsart University Sriracha Campus, Thailand. And, his research interest areas include applied linguistics, communication strategies and English for specific purposes. 